\title{
Intrauterine Foetal Death: A Hospital Based Study
}

\author{
Jahan $\mathrm{K}^{1}$, Mahaseth $\mathrm{BK}^{1}$
}

\begin{abstract}
Introduction: Foetal death at any stage of pregnancy is not just a tragic event but also a more traumatic for the mental well-being of a mother. It is one of the most wrenching events in the field of obstetrics. Aims: The study was done to determine the probable risk factors of intrauterine foetal death and role of antenatal care in its prevention. Methods: The study was conducted in Obstetrics and Gynecology department at Nepalgunj Medical college from July 2018 to July 2020 .Inclusion criteria were intrauterine fetal death of $>28$ weeks of gestation and baby weighing 1000 grams or more . An exclusion criterion was molar pregnancy. Results: There were $115(3.52 \%)$ intrauterine fetal death during the study period, making it 35 per 1000 cases. In $17(14.78 \%)$ the cause of intrauterine fetal death was not known. The other common associated risk factors were prematurity in $14(12.17 \%)$ and hypertension in 13(11.30\%). Similarly anemia and antepartum hemorrhage were seen in $13(11.30 \%)$ each. $11(9.56 \%)$ patients had oligohydramnios. Mal presentation was found in $8(6.95 \%)$ patients while polyhydromnios in $6(5.21 \%)$.The commonest age range in whom intrauterine fetal death was seen was 20-30 (73.90\%). 28 (24.34\%) patients were at preterm pregnancy ranging between 28-30 weeks whereas 17(14.78) intrauterine fetal death occured at 32-34 weeks. 77 foetuses were preterm and their birth weight was between $1-1.5 \mathrm{~kg}$ with the mean wt of $1175.73 \mathrm{gms}$. Conclusion: Intrauterine fetal death is still common inspite of the improving awareness in importance of regular antenatal care. In majority, the cause of intrauterine fetal death is still unknown. However, where the cause was known prematurity was the commonest.
\end{abstract}

Keywords: Birth weight, Intrauterine death, Prematurity, Risk factors

Authors:

1. Dr. Kamar Jahan

2. Dr. Binod Kumar Mahaseth

Department of Obstretics \& Gynaecology, Nepalgunj Medical College and Teaching Hospital

\section{Address for Correspondence:}

Dr. Kamar Jahan

Lecturer

Department of Obstretics \& Gynaecology

Nepalgunj Medical College and Teaching Hospital

Nepalgunj, Banke

Email: ayaazkamar@gmail.com

\section{INTRODUCTION}

Intrauterine foetal death (IUFD) is defined as death prior to the complete expulsion from mother of a product of conception after the age of viability (according to American College of Obstetricians and Gynecologists, ACOG 22 weeks). ${ }^{1}$ However, conventionally $28^{\text {th }}$ weeks of the gestation is considered as the period of viability in most developing countries including Nepal. ${ }^{2}$ Prematurity is one of the most common causes of morbidity and perinatal death. ${ }^{3}$ Some cases of IUFD cannot be prevented but the risk can be reduced by being aware and taking preventive measures. Besides being emotionally challenging for the mother, attendant, obstetrician and the nursing staff, foetal demise raises a lots of questions and medicolegal risk. Illiteracy, poor socioeconomic condition of women and misbelieves are important contributory factors responsible for higher foetal mortality rate. It is appreciable that grief response following IUFD is severe. It is probably most traumatic experience that women undergo in her life and takes about months for them to return to normal routine life. ${ }^{4}$
Newer techniques of diagnosis and a better understanding of pathophysiology have led to the determination of cause of death in a greater proportion of foetal deaths. ${ }^{5}$

This heterogeneity in the definition of foetal death makes it difficult to compare incidences in the different populations observed and accurately assess the extent of the problem. Every year worldwide there are about 2.6 million IUFD are reported, ${ }^{6}$ with an incidence ranging from 3.4 per thousand to 36 in the Sub-Saharan and Southern Asia regions. ${ }^{7}$

\section{METHODS}

This was a hospital based study conducted in Obstetrics and Gynecology department at Nepalgunj Medical College from July 2018 to July 2020. The ethical clearance was taken from the Institutional Review Committee before conducting the study. Informed and written consent was taken from the patients. Detailed history and through clinical examination of the patients were done and vitals recorded. Complete blood count, renal and liver function tests and random blood sugar 
were done. The regularity of antenatal checkup was studied. Obstetric ultrasound was done and in case of any abnormality present, that was recorded. When IUFD was suspected, the diagnosis was confirmed by ultrasound. The gestational age was confirmed by clinical examination by dating from Naegle's rule or by ultrasonography. Once IUFD was confirmed the fetal expulsion was done either with Misoprostol or caesarian section whenever indicated. All cases of IUFD $>28$ weeks of gestation and babies weighing 1000 grams or more were included. The cases of molar pregnancy diagnosed by ultrasonography were excluded.

\section{RESULTS}

The total number of deliveries was 3261 during our study period. The number of intrauterine foetal deaths was 115 (3.52\%). IUFD was detected in $13(11.3 \%)$ young mothers of age less than 20 whereas maximum number of mothers was between $20-30$ years of age, i.e. $85(73.9 \%)$. Similarly $17(14.78 \%)$ mothers were in between age 31-40 (Table I).

\begin{tabular}{ccc|}
\hline Age(weeks) & Number. of cases & Percentage \\
\hline$<20$ & 13 & $11.30 \%$ \\
\hline $20-30$ & 85 & $73.90 \%$ \\
$31-40$ & 17 & $14.78 \%$ \\
\hline
\end{tabular}

Table I: Maternal age

The most common cause of IUFD was found to be prematurity, i.e. $14(12.17 \%)$ whereas no cause was identified in around $17(14.78 \%)$ cases. Anemia, hypertension and antepartum hemorrhage (APH) were diagnosed in $13(11.30 \%)$ cases each. The other causes were oligohydramnios (9.5\%), polyhydramnios (5.2\%), obstructed labour (4.34\%) and ruptured uterus $(3.47 \%)$ (Table II).

$\begin{array}{lcc}\text { Causes } & \begin{array}{c}\text { Number. of } \\ \text { cases }\end{array} & \text { Percentage } \\ \text { Unknown } & 17 & 14.78 \% \\ \text { Premature } & 14 & 12.17 \% \\ \text { APH } & 13 & 11.30 \% \\ \text { Hypertension } & 13 & 11.30 \% \\ \text { Anemia } & 13 & 11.30 \% \\ \text { Oligohydramnios } & 11 & 9.56 \% \\ \text { Malpresentation } & 8 & 6.95 \% \\ \text { Polyhydromnios } & 6 & 5.21 \% \\ \text { Sepsis } & 5 & 4.34 \% \\ \text { Obstructed Labor } & 5 & 4.34 \% \\ \text { Ruptured Uterus } & 4 & 3.47 \% \\ \text { Hydrocephalus } & 3 & 2.60 \% \\ \text { Diabetes Mellitus } & 2 & 1.73 \% \\ \text { Omphalocele } & 1 & 0.86 \%\end{array}$

Table II: Causes of Intra-Uterine foetal death
In 41 cases the birth weight was in between 1000 grams to 1500 grams. Amongst these cases 23 were in gestational age of 28-30 weeks. Similarly 21 patients were having dead fetus of 1501-2000 grams.12 patients had fetus of 2100- 2500 grams and 29 patients had fetus of 2501-3000 grams. 10 fetus were of 3001 -3500grams whereas only 2 fetus were more than 3500gms in weight (Table III). Only 38(33.04\%) ladies did regular antennal visit record. 56(48.69\%) ladies had irregular antenatal checkup and $21(18.26 \%)$ did not do antennal checkup at all.

\begin{tabular}{|ccccccccc}
$\begin{array}{c}\text { Gestational } \\
\text { age in } \\
\text { weeks }\end{array}$ & $\begin{array}{c}1000- \\
\mathbf{1 5 0 0} \\
\text { gms }\end{array}$ & $\begin{array}{c}\mathbf{1 5 0 1 -} \\
\mathbf{2 0 0 0}\end{array}$ & $\begin{array}{c}\mathbf{2 1 0 0}- \\
\mathbf{2 5 0 0}\end{array}$ & $\begin{array}{c}\mathbf{2 5 0 1 -} \\
\mathbf{3 0 0 0}\end{array}$ & $\begin{array}{c}\mathbf{3 0 0 1 -} \\
\mathbf{3 5 0 0}\end{array}$ & $\mathbf{> 3 5 0 0}$ & Total & Percentage \\
\hline $28-30$ & 23 & 5 & 0 & 0 & 0 & 0 & 28 & 24.34 \\
\hline $31-33$ & 10 & 1 & 1 & 1 & 1 & 0 & 14 & 12.17 \\
\hline $34-36$ & 6 & 10 & 4 & 14 & 1 & 0 & 35 & 30.43 \\
\hline $37-39$ & 2 & 5 & 6 & 11 & 3 & 2 & 29 & 25.21 \\
\hline $40-42$ & 0 & 0 & 1 & 3 & 5 & 0 & 9 & 7.82 \\
\hline Total & 41 & $\mathbf{2 1}$ & 12 & $\mathbf{2 9}$ & 10 & 2 & 115 & 100 \\
\hline Percentage & 35.6 & & & & & & & \\
\hline
\end{tabular}

Table III: Birth weight and gestational age distribution of IUFD

\section{DISCUSSION}

Intrauterine fetal death is the most disheartening event in the field of obstetrics. In the view of importance of decreasing fetal death rate, the government has even introduced the programme like safe motherhood under which the deliveries are conducted for free of cost. The rate of intrauterine fetal death in our study is almost similar to the study by Sushmita sharma et $\mathrm{al}^{8}$ while it is greater than study by Anjali $\mathrm{C}$ et al. ${ }^{9}$ Early marriages and illiteracy might have been the reasons for the greater rate of IUFD in our study. In around $14.78 \%$ cases of our study causes could not be determined which corresponds to the one found in other study. ${ }^{14}$ Amongst the causes prematurity was the most common cause (12.1\%) which corresponds to the previous study by Chaitra et al. ${ }^{10}$ Majority of fetuses were preterm and the birth weight was between $1-1.5 \mathrm{~kg}$ (35.5\%). In 73.9\% of cases the mothers were of age between 20- 30 which corresponds to the study by nayak et al. ${ }^{11}$

Hypertension was seen in $11.3 \%$ of mothers which is less than the study by Nandini et al. ${ }^{12}$ Preeclampsia and eclampsia both can be prevented if the patient is advised antihypertensive during their antenatal visits. The present study showed diabetes mellitus as a cause in $1.73 \%$ cases while other showed it $13 \%$ which is more than our observation..$^{13}$ We observed anemia in $11.3 \%$ mothers whereas Jamal et al found in $25 \%$ cases. ${ }^{14}$ Anemia and diabetes mellitus both can be controlled by dietary factors and medicines. Similar no of cases $(11.3 \%)$ were found to have APH in our study which is similar to finding of Sharma et al $12 \%{ }^{8}$ However it is wise to advise the parents for tests for chromosomal abnormalities if there is past history of birth of anomalous babies. Oligohydramnios 
and polyhydramnios were detected in $9.5 \%$ and $5.2 \%$ cases respectively whereas Patel $\mathrm{S}$ et al observed oligohydramnios in $8.19 \%$ cases and polyhydramnios in $1.67 \%$ cases (15). These factors can be detected earlier than the mishap if the patient follows up for antenatal checkups regularly. The presentation of fetuses in uterus was other than vertex in around $6.95 \%$ and this finding is similar to the many studies. ${ }^{16} 4.34 \%$ mothers presented in sepsis in whom the fetus were found dead. ${ }^{17}$

Since our center is the tertiary place for referral of complicated cases, the patient cannot reach the hospital on appropriate time and the delay leads to such an unpleasant output. There is no doubt that there may also be unknown pathological factors in the biochemical, genetic, or immunological field, which do not allow for a complete identification of the pathologies leading to IUFD in all cases.

\section{CONCLUSION}

The most common cause of IUFD is not known. Different etiological factors responsible for IUFD are poor health seeking behavior, poverty, illiteracy, poor nutrition etc. Despite availability of modern intervention like non stress test, ultrasonography majority of causes of IUFD remains unknown. In our study young maternal age and associated co morbidities like anemia, hypertension and diabetes mellitus were the major maternal causes of IUFD while most common foetal causes were preterm babies and anomalous baby. Early diagnosis and termination of pregnancy remains keystone for prevention of IUFD and can be prevented by early registration of pregnancy, good nutrition, regular female centered ANC visits and early referral to tertiary center.

\section{REFERENCES}

1. Olyai R, Mittal C. Foetal death. In.Dutta D K, editor. Recent advances in high riskpregnancy. India: Jaypee Brothers Medical Publishers (P) Ltd; 2010. P155-64

2. Finney, Patrick A. Moral Problems in Hospital Practice: a Practical Handbook. St. Louis: Herder Bk. Co. 2002; 24.

3. Moore, Keith and Persaud, T. The Developing Human: Clinically Oriented Embryology. Saunders 2003; 103-9.

4. Reddy UM. Prediction and prevention of recurrent stillbirth. Obstet Gynecol. 2007 Nov;110(5):1151-63

5. Safarzadeh A, Ghaedniajahromi M, Ghaedniajahromi M, Rigi F, Massori N. Intra uterine foetal death and some related factors: A silent tragedy in South-eastern Iran. J Pain Relief. 2014;3:129

6. Facchinetti F, Alberico S, Benedetto C, et al. A multicenter, case-controlstudy on risk factors for antepartum stillbirth. J MaternFoetal Neonatal Med.2011;24(3):407-10.

7. Blencowe $\mathrm{H}$, Cousens $\mathrm{S}$, Jassir FB, et al. National, regional, and world widen estimates of stillbirth rates in 2015, with trends from 2000: a systematic analysis. Lancet Glob Health. 2016;4(2):e98-e108.

8. Sharma S, Sindhu H, Kaur S. Analytical study intrauterine foetal death cases and associated maternal conditions. Int.J Appl Basic Med Res. 2016;6(1);11-13

9. Anjali C, Gupta V. Epidemiology of intrauterine foetal deaths: A study in tertiary referral centre in Uttarakhand. IOSR-JDMS. 2014;13(3):3-6.

10. Chaitra S,et.al, "Intrauterine Foetal Deaths: A Study in Tertiary Care Center". ARC Journal of Gynecology and Obstetrics. 2018; 3(1) : 7-10.

11. Nayak SR, Garg N. Determination of antepartum foetal death. J Obstet Gynecol India. 2010 Dec;60(6):494-7.

12. Natarajan N, Putnam W, Van Aarsen K, Beverley Lawson $\mathrm{K}$, Burge $\mathrm{F}$. Adherence to antihypertensive medications among family practice patients with diabetes mellitus and hypertension. Can Fam Physician. 2013 Feb;59(2):e93-e100. PMID: 23418264; PMCID: PMC3576963.

13. Desai S, Savant V. Evaluation of clinical and aetiological factors for intrauterine foetal death. Online Int Interdiscipl Res J 2014;4(1).112-115

14. Jamal S, Agarwal S. IUFD incidence, causes and complications: a retrospective study done at a tertiary care centre in greater Noida, India. Int J Reprod Contracept ObstetGynaecol 2017;6(12):5483-7.

15. Patel S, Thaker R, Shah P, Majumder S. Study of causes and complications of intra uterine foetal death (IUFD). Int J Reprod Contracept Obstet Gynecol. 2014;3:931-5.

16. Safarzadeh A, Ghaedniajahromi M, Rigi F, Massori N. Intra uterine foetal death and some related factors: A silent tragedy in Southeastern Iran. J Pain Relief. 2014;3:1.275-278

17. Choudhary A, Gupta V. Epidemiology of Intrauterine Foetal Deaths: A Study in Tertiary Referral Centre In Uttarakhand. Journal of Dental and Medical Sciences. 2014;13(3):3-6. 